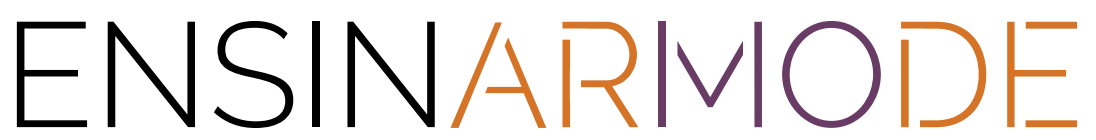

Revista de Ensino em Artes, Moda e Design

\title{
Dossiê 7
}

Educação e Design Participativo

\section{OFICINA O CASACO DE MARX: ENTRE A MODA, O DESIGN, A ANTROPOLOGIA E A SEMIÓTICA ${ }^{1}$}

Marx's Coat Workshop: Between Fashion, Design, Anthropology and Semiotics

Taller el Abrigo de Marx: Entre la moda, el diseño, la antropología y la semiótica

Maira Pereira Gouveia Coelho Juliana Rocha Franco ${ }^{3}$ 


\title{
Resumo
}

O artigo tem como objetivo analisar a oficina "O casaco de Marx", elaborada e coordenada por Maira Gouveia, ação performática contingente inspirada nas imbricações poéticas da vestimenta com seus usuários relatadas no livro homônimo do historiador Peter Stallybrass (2012). Como metodologia, a oficina possui um caráter prático-reflexivo e propõe exercícios que dialogam com os campos da semiótica e da antropologia, utilizando questionamentos e apontamentos da moda e do design para tecer uma leitura crítico-reflexiva sobre as possibilidades de relações a serem construídas com os objetos do cotidiano. Ao longo da investigação, foi possivel observar modos de ocorrência de diálogos entre os campos do design, da moda, da antropologia e da semiótica, para repensar o nosso olhar sobre a cultura material e propor uma relação mais significativa com os artefatos que nos circundam, a partir da compreensão do realismo agencial de Karen Barad. Ou seja, pensar na oficina a possibilidade de compreensão dos objetos como agentes sociais enquanto cocriadores de nossos modos de existência.

Palavras-chave: Moda; Design; Cultura Material.

\begin{abstract}
The paper aims to analyze the workshop "The coat of Marx," designed and coordinated by Maira Gouveia. The workshop is an action inspired by the coat's poetics overlays with its users reported in Peter Stallybrass's same title's book (2012). As a methodology, the workshop has a practical-reflective character. It proposes exercises that dialogue with the fields of semiotics and anthropology, using questions and reflections from fashion theory and the field of design to weave a critical-reflective reading on the possibilities of relationships to be built with everyday objects. Throughout the investigation, it was possible to observe ways of occurring dialogues between design, fashion, anthropology, and semiotics to rethink our look at material culture. Moreover, the workshop proposes a more significant relationship with the artifacts surrounding us, from Karen Barad's agential realism to think in the workshop, the possibility of understanding objects as social agents as co-creators of our ways of living.
\end{abstract}

Keywords: Fashion; Design; Material Culture.

\footnotetext{
${ }^{1}$ Pesquisa patrocinada pela CAPES.

${ }^{2}$ Maira Gouveia é mestranda em Design (UEMG) e graduada em Design de Moda (UFMG). Possui especialização em Artes Visuais pelo Cefart (2018) e experiência como docente em países da Ásia e América Latina. | Lattes: http://lattes.cnpq. br/4092954906588263 | Orcid: https://orcid.org/0000-0002-6837-0046 |E-mail: mairagouveia@gmail.com 3 Juliana Rocha Franco é doutora em Comunicação e Semiótica (PUC-SP), mestre em Comunicação Social (UFMG). Professora da Universidade Estadual de Minas Gerais (UEMG) nos cursos de Graduação e Pós-Graduação da Escola de Design (UEMG) e pesquisadora do Centro de Pesquisa em Design e Ergonomia (CPqD-UEMG). | Lattes: http://lattes.cnpq.br/7531722640128367 | Orcid:https://orcid.org/0000-0001-7021-3341 | E-mail: julianarochafranco@gmail.com
} 


\section{Resumen}

El trabajo tiene como objetivo analizar el taller "El abrigo de Marx", diseñado y coordinado por Maira Gouveia. El taller es una acción inspirada en las superposiciones poéticas del abrigo con sus usuarios informados en el libro del mismo título de Peter Stallybrass (2012). Como metodología, el taller tiene un carácter práctico-reflexivo. Propone ejercicios que dialogan con los campos de la semiótica y la antropología, utilizando preguntas y reflexiones de la teoría de la moda y el campo del diseño para tejer una lectura crítica reflexiva sobre las posibilidades de construir relaciones con objetos cotidianos. A lo largo de la investigación, fue posible observar formas de diálogo entre diseño, moda, antropología y semiótica para repensar nuestra visión de la cultura material. Además, el taller propone una relación más significativa con los artefactos que nos rodean, desde el realismo agencial de Karen Barad para pensar en el taller, la posibilidad de entender los objetos como agentes sociales como cocreadores de nuestras formas de vida.

Palabras-clave: Moda; Diseño; Cultura material. 


\title{
1 INTRODUÇÃo
}

\author{
José Saramago \\ "O casaco \\ Um homem estava anoitecido \\ Se sentia por dentro um trapo social \\ Igual se, por fora, usasse por um casaco rasgado \\ E sujo. \\ Tentou sair da angústia \\ Isto ser: \\ Ele queria jogar o casaco rasgado e sujo no lixo. \\ Ele queria amanhecer." \\ Manoel de Barros
}

"A gabardina aderia ao encosto do banco, do mesmo modo que ao casaco, à camisola de lã, à camisa, à camisola interior, à pele, aos músculos, aos ossos."

A oficina foi pensada e elaborada pela propositora Maira Gouveia em 2016, após a leitura do livro do historiador Peter Stallybrass O Casaco de Marx: roupas, memória, dor (2012), durante o período em que trabalhou como docente na Índia. O delineamento inicial da composição para finalidades performáticas surgiu a partir da experiência deixada pela leitura do livro, quatro anos após sua leitura. A partir de uma abordagem prática-reflexiva, a atividade busca trazer para o mundo material algumas das questões suscitadas pela obra. A oficina surge, então, a partir da busca de compreender, como os objetos, nesse caso mais especificamente, as vestimentas, agem e fazem parte da nossa construção social, afetiva e simbólica.

Em 2018, a oficina foi realizada pela primeira vez na Universidade Autônoma do México, durante o II Colóquio de Diseño Sustentable. De 2018 a 2019, foi ministrada em mais de vinte eventos acadêmicos promovidos por diversas instituições de ensino: UNAM (México, 2018), USP (2019), UDESC (2018), UFMG (2018), UEMG (2018), CEFART (2019), CEFET-MG (2019), além de museus e centros culturais, contando com uma média de 400 participantes, no total. $O$ público participante da experiência é em geral oriundo de contextos heterogêneos, mas o foco inicial seu deu em estudantes de moda, design e arte. Todavia, a oficina também foi ministrada para alunos do ensino superior nos cursos de teatro, sociologia e arquitetura, para professores do ensino básico, alunos do ensino técnico e médio, público livre e terceira idade, entre outros. É importante ressaltar que a configuração inicial da proposta original vem se modificando constantemente a partir das trocas, ideias e discussões que surgem ao longo de seu decorrer e que, a cada edição, tornam as questões trabalhadas mais profícuas e complexas.

Como evocado poeticamente por José Saramago (1978) e Manoel de Barros (1996) nos trechos acima, a roupa não somente nos veste, ela possui a capacidade de aderir ao nosso corpo, pele e ossos. O vestuário nos representa, reveste e constrói de muitas e diferentes maneiras profundas e simbólicas. Ancorada por tal pressuposto, o trabalho performático possibilitado pela oficina busca elucidar, mais que interações ${ }^{1}$ entre roupa e corpo, intrações

${ }^{1}$ Conceito cunhado por Karen Barad (2007), a intração difere da interação por não considerar duas entidades anteriores à experiência, segundo a autora, nos configuramos sempre a partir do encontro. 
vestimentares a partir de uma experiência empírica, conduzida através da prática-reflexiva (SCHÖN, 2000).

Ao longo do artigo, apresentaremos brevemente um resumo dos principais conceitos presentes na obra que inspirou a criação da oficina para, em seguida, descrever e analisar o trabalho experimental em seu diálogo com o livro. Discorreremos ainda sobre o processo metodológico que fundamentou sua composição e, por fim, analisaremos alguns possiveis modos de integração dos campos da moda, do design, da semiótica e da antropologia no intuito de repensar nossas relações com a cultura material a partir dos conceitos de realismo agencial e de intração (BARAD, 2007) trabalhados na experiência descrita neste artigo.

Figura 1: Oficina ministrada em Maio de 2018 na Universidade Autônoma do México.
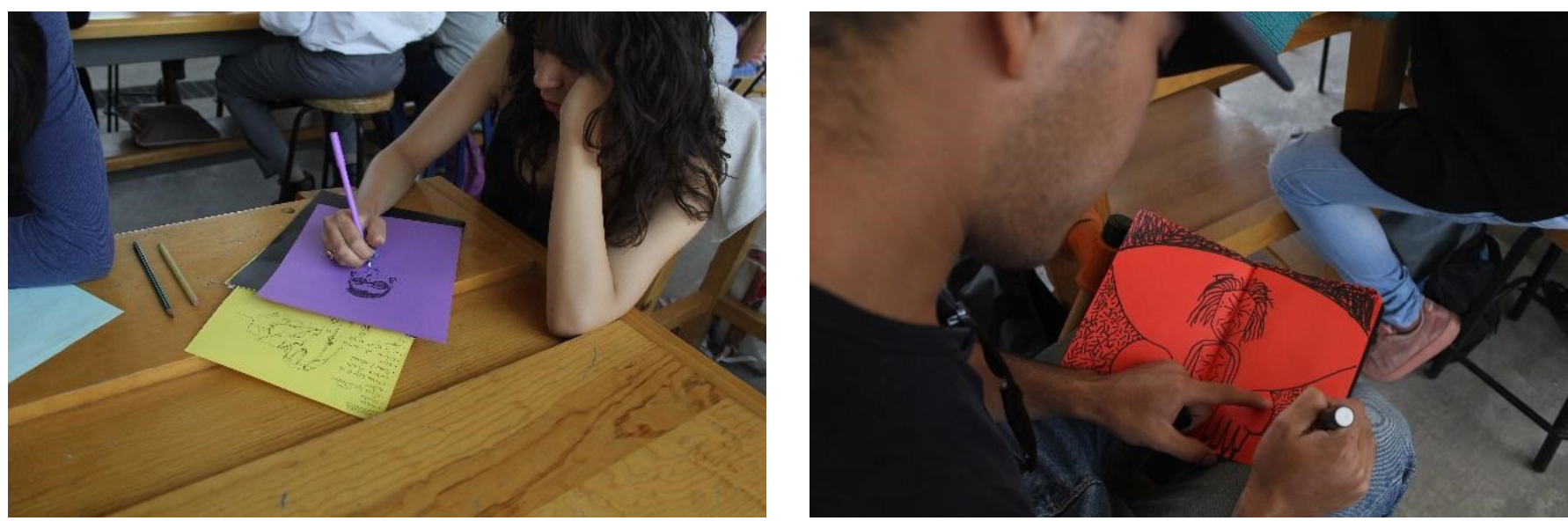

Fonte: Autoras

Assim, nas palavras da autora: "Na minha elaboração realista agencial, os fenômenos não marcam meramente a inseparabilidade epistemológica do observador e observado, ou os resultados das medições; ao contrário, os fenômenos são a inseparabilidade ontológica de componentes agencialmente intra-ativos." (2007, p.139. Tradução Nossa do original "In my agential realist elaboration, phenomena do not merely mark the epistemological inseparability of observer and observed, or the results of measurements; rather, phenomena are the ontological inseparability 1 entanglement qf intraacting "agencies."). 
Como principio fundamental, a oficina busca compreender as interseções possiveis que permitem criar uma análise simultaneamente semiótica e antropológica a partir do design e da moda, desvelando os signos possíveis e concomitantemente compreendendo a perspectiva antropológica dos objetos como dotados de "agência" (BARAD, 2007; MILLER, 2013; GELL, 2018) "vida" (INGOLD, 2012) e capacidade de "participação" (GELL, 2018). Ou seja, os casacos são compreendidos, durante a oficina, como participantes ativos das relações sociais e afetivas que os participantes vivenciam e expressam. Dessa forma, o que se propõe é a compreensão dos processos de produção de sentidos tecidos em teias de relações nas quais os artefatos estão incluidos e nas quais são compreendidos como atuantes no processo de criação de semioses possíveis (SANTAELLA et al, 2011; FRANCO e NEVES, 2017), estas compreendidas como processo de produção de sentido a partir do encadeamento sígnico construido a partir de redes de "relações transversais entre corpos, objetos, animais, tecnologia, materialidade, textos, individuos, isto é, entre elementos heterogêneos" (FRANCO, 2019. p. 151).

A proposta consiste, desse modo, em compreender em que medida a oficina abre modos possiveis para que o público problematize uma visão de si, do mundo e das coisas construídas e sedimentadas culturalmente a partir de pares opositores binários ou diádicos (sujeito/ objeto, masculino/feminino, local/global, etc.). Conforme afirma Franco (2019), o pensamento diádico fundamenta o raciocínio ocidental convencional, estruturado logicamente a partir do axioma do terceiro excluido e pelo princípio da não contradição, possibilitando uma ontologia na qual as coisas se configurariam em termos de A/não-A, B/não-B:

Tal forma de pensar tende a ver as coisas em termos de relações de oposição e de exclusão binárias entre "essências puras", supostamente dicotômicas ou mutuamente exclusivas (A/não-A), e não como condensações de muitos fenômenos diferentes, eventos e aspectos articulados complexamente (FRANCO, 2019, p.69).

Uma vez que o trabalho busca mostrar como a oficina se estrutura a partir da agência dos objetos, interessa, sobremaneira, pensar possibilidades teóricas para se ultrapassar a compreensão da relação diádica sujeito/objeto, já que, a compreensão do processo de produção de sentido como uma rede semiótica implica justamente em reconhecer a agência dos objetos, que, dessa forma, deixariam de se enquadrar na relação diádica sujeito/objeto. Pensar o processo de semiose a partir do encadeamento sígnico de três elementos (Signo, objeto e interpretante) se apresenta, conforme afirmam Franco e Borges (2015), como uma alternativa para se compreender os fenômenos contemporâneos para além de teorias que consideram "signos e realidade para sempre divorciados, em vez de integrados numa continuidade natureza-cultura" (ANDACHT apud FRANCO e BORGES 2015, p. 1".

\section{SOBRE O LIVRO}

O livro o Casaco De Marx: roupas, memória, dor, escrito por Peter Stallybrass e publicado em 2012 pela Editora Autêntica, parte de uma premissa simples: através da análise dos obje- 
tos, em especial de vestuários em sua relação com os corpos humanos que os habitam bem como com as teias sociais em que estes se emaranham, como proposto por Barad (2007), o historiador investiga a nossa relação com a cultura material circundante. Ele propõe pensar os artefatos não apenas enquanto objetos de uso ou como mercadorias; no livro, considera-se principalmente marcas e memórias que imprimimos nos objetos e aquelas que eles nos imprimem de volta, tanto de forma individual quanto social. O livro é dividido em três capítulos, "A vida social das coisas: roupas, memória, dor", "O casaco de Marx" e "O mistério do Caminhar". A seguir, detalharemos rapidamente cada um deles.

No capítulo: "Vida social das coisas", Stallybrass lança um olhar social e afetivo sobre a história da vestimenta ressaltando e analisando não somente os aspectos socioeconômicos dos relatos que envolvem tecidos e roupas, que destaca no seu estudo, mas também analisa concomitantemente como as pessoas constroem relações simbólicas, revelam conexões amorosas e familiares e constroem um registro histórico de si mesmas a partir do vestuário. Como o próprio autor relata:

Numa sociedade da roupa, pois, a roupa é tanto uma moeda quanto um meio de incorporação. (...) ela prende as pessoas em rede de obrigações. O poder particular da roupa para efetivar essas redes está estreitamente associado a dois aspectos quase contraditórios de sua materialidade: sua capacidade de ser permeada e transformada tanto pelo fabricante quanto por quem a veste; e sua capacidade de durar no tempo. A roupa tende, pois, a estar poderosamente associada com a memória, ou para dizer de forma mais forte, a roupa é um tipo de memória. (STALLYBRASS, 2012 p.14)

A partir dessa perspectiva, Stallybrass trilhará um percurso por meio do qual visitará uma série de autores incluindo Vladimir Nabokov, um poema de Laurence Lerner, um relato de Nina Payne, incluindo a autobiografia de Philip Roth, a poesia de Pablo Neruda, além de relatos de documentos históricos de operários e trabalhadores comuns. Desta feita, através de cartas, entre outras diversas fontes históricas, literárias e poéticas, o pesquisador traça um trajeto que ilustra a memória carregada pelos objetos e seu valor na trama social.

No segundo capítulo homônimo ao livro, "O casaco de Marx", o autor apresenta o casaco a partir da perspectiva da história do teórico Karl Marx, reavaliando-o não somente enquanto objeto mercadoria, na qual "(...) o casaco, qualquer casaco, (é) visto como um valor de troca, é esvaziado de qualquer função útil" (STALLYBRASS, 2012, p.41), mas, também, cria um paralelo com a relação de Karl Marx com o seu próprio casaco que lhe auxiliava a se sustentar não somente economicamente, mas, social e intelectualmente, através do status que a vestimenta the garantia. Ou seja, analisando o casaco por sua utilidade prática e também simbólica na vida de Marx, como vemos a seguir:

Um negociante de objetos de segunda mão poderia ter se envergonhado, mas os Marx não podiam se dar ao luxo de se sentirem envergonhados. Seus móveis quebrados, suas panelas e frigideiras, seus talheres, suas próprias roupas, tinham um valor de troca. E eles sabiam exatamente qual era esse valor, uma vez que cada peça de seus pertences tinha feito o trajeto de ida e volta entre sua casa e a loja de penhores. (STALLYBRASS, 2012, p.51)

Como o Stallybrass afirma, os objetos de Marx e de sua familia, inclusas as roupas e seu casaco, estavam constantemente na casa de penhores e, segundo cartas trocadas com 
Engels, quando não tinha condições de resgatar seu casaco, Marx nem mesmo podia frequentar a biblioteca, pausando, desta maneira, o seu processo de estudos e a escrita de seus livros. As dimensões afetivas e a necessidade econômica ligadas ao casaco e ao processo de penhora podem ser notadas no seguinte trecho: "Ontem penhorei um casaco que remontava a meus dias de Liverpool, a fim de comprar papel para escrever" (MARX apud STALLYBRASS, 2012, p. 79).

No terceiro capítulo, "O mistério do Caminhar", Stallybrass presta uma homenagem ao seu pai, a partir do enigma da Esfinge proposto à Édipo: aquele ser que de manhã teria quatro pernas, de tarde duas e ao anoitecer três. Como é sabido, a questão se refere ao ser humano em suas diversas fases: da tenra infância, passando pela fase adulta, até a velhice. Assim, o autor analisa a bengala como esse objeto de autonomia e interdependência, ou seja, do objeto de que dependemos para continuar a caminhar.

No decorrer do capítulo, Stallybrass defende a tese de que nunca andamos somente em duas patas, como afirma a Esfinge, ou seja, nunca estamos sozinhos caminhando somente sobre nossos próprios pés. Ele elucida no texto que o que a criança faz nada mais é do que internalizar o equilibrio gerado pela "terceira perna", pois aprendemos a caminhar nos segurando sempre em algo: nos apoiando numa cadeira, nas mãos de nossos pais. Desta forma, a internalização desse terceiro apoio, deste outro, é o que nos permite caminhar, ou seja, nunca caminhamos sozinhos. O autor tece um paralelo com a história de próprio Édipo e traça um texto poético que nos faz refletir sobre o lugar que os objetos ocupam em nossas vidas e como necessitamos deles para nossa constituição.

Como o próprio Stallybrass descreve, o livro surge da necessidade de entender como, utilizando o casaco de um amigo que havia falecido, foi "habitado por sua presença" (2012, p. 10). Ele afirma que enquanto vestia a jaqueta de seu amigo falecido, seu amigo o vestia, ou seja, sua memória permanecera na roupa que uma vez o vestira, "ele estava lá no cheiro", "nos puimentos do cotovelo (...) chamados de "memória"" (2012, p. 11). Stallybrass resgata, portanto, o conceito de fetiche como a magia contida nas coisas para explicar essa relação de "agência" que os objetos constroem conosco segundo a antropologia (BARAD, 2007; GELL, 2015: INGOLD, 2012; MILLER, 2013), ou o surgimento de um interpretante a partir da semiótica Peirciana (SANTAELLA et al 2014). Portanto, a oficina sobre a qual discorreremos a seguir utiliza como base uma busca fenomenológica do objeto para conectar os conceitos presentes nas teorias acima na forma de uma trama, buscando uma abordagem multidisciplinar e integrada a ser trabalhada de forma prática no curso homônimo ao livro: "O Casaco de Marx".

\section{METODOLOGIA}

A Oficina de que trata este artigo foi idealizada a partir das memórias reminiscentes causadas pelas reflexões propostas no livro. Na tentativa de trazer os questionamentos que surgiram com a leitura para uma experiência prática, articulou-se uma oficina que se divide em seis etapas. No final de cada uma destas etapas, há uma discussão em forma de compartilhamento de resultados entre os participantes e demais componentes do grupo. 
Como objetivo, a oficina visa a instigar reflexões sobre a memória corpórea afetiva que cada objeto carrega. Buscamos, de forma prática, gerar uma nova consciência e visão sobre os objetos do dia-a-dia para repensar a forma como consumimos, projetamos e materializamos objetos. Trazer novas perspectivas, não apenas sobre os objetos como bens utilitários, mas estimular a apreensão de outros valores, signos e mensagens que o objeto pode cocriar. Como propõe Tim Ingold (2012), ao considerar que os materiais existem e se apresentam em fluxo, pretendemos de forma prática retomar "essa asserção na forma de uma regra simples: seguir os materiais (...) matéria em fluxo. Seguir esses materiais é entrar num mundo, por assim dizer, em fervura constante.", ou seja, acompanhar essa ecceidade de que falam Deleuze e Guattari (INGOLD, 2012, p. 38), em seus caminhos e descaminhos.

Figura 2: Oficina ministrada em Setembro de 2018 na Universidade do Estado de Santa Catarina.
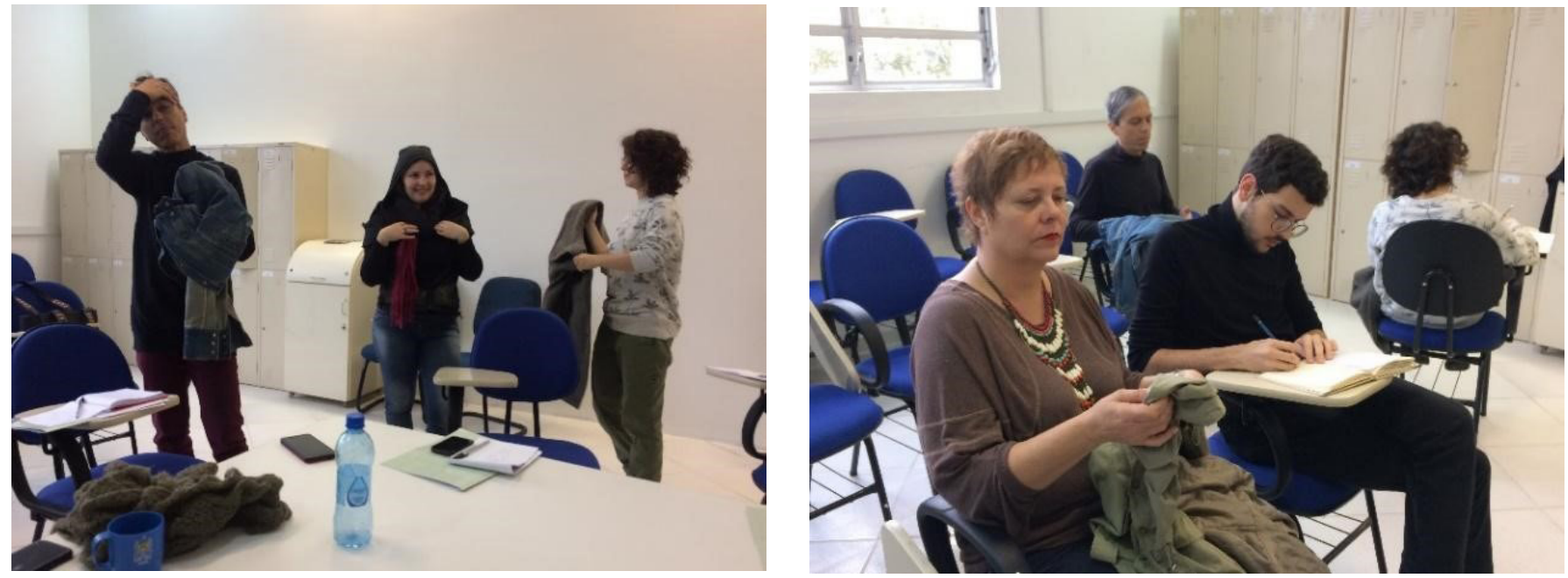

Fonte: Autoras.

Durante a oficina busca-se, simultaneamente, captar as redes semióticas de produção de sentido (semiose); nesse contexto, compreende-se o próprio artefato como um signo. As 
semioses são acionadas com questões de história, forma e função, ergonomia, afetividades, métodos de construção, materialidades. No entanto, o foco se dá principalmente a partir das perspectivas das imaterialidades simbólicas, bem como dos fetiches e dos valores agregados.

Com isso, a oficina "O casaco de Marx" intenta abarcar indagações caras ao campo de estudo do design e da moda: questões imateriais do objeto e sua relação com o sujeito. Também tem como resultado um viés prático, a partir de experimentações com ilustrações, desenhos, colagens e escrita poética geradas pelo manuseio do objeto que se materializam em diversos gêneros narrativos e literários. A oficina parte metodologicamente de uma análise fenomenológica do objeto, ou seja:

\begin{abstract}
Se propõe revelar o mundo como ele é de fato experienciado pelo sujeito, de modo direto, e não como poderiamos, pela via teórica, supor que ele é. O objetivo não é explicar o mundo (em termos, digamos, de casualidades físicas ou acontecimentos históricos ou disposições psicológicas), mas descrevê-lo, o mais precisamente possível, nos conformes em que os seres humanos o experienciam. Tal descrição, se bem sucedida, é necessariamente uma re-descrição e, portanto, pode levar a novos insights e novos conhecimentos sobre o que há no mundo e como ele afeta a consciência humana, e vice-versa. A fenomenologia é antes um estilo ou modo de pensar do que um conjunto de doutrinas, normas ou procedimentos que podem ser seguidos; um modo de Ser no mundo e um modo de pensar sobre ele. (TILLEY, 2014, p.23)
\end{abstract}

A partir desta abordagem inicial, aproxima-se da semiótica peirceana em busca dos signos e semioses desencadeadas pelo artefato. Peirce criou uma fenomenologia própria, assentada nas suas categorias fenomenológicas (SANTAELLA et al. 2011). Sobre as relações entre Peirce e a fenomenologia podemos ver o seguinte:

Como ponto de partida, sem nenhum pressuposto de qualquer espécie, Peirce voltou-se para a experiência ela mesma. Como entidade experienciável (fenômeno ou phaneron), considerou tudo aquilo que aparece à mente. Sem nenhuma moldura preestabelecida, sua noção de fenômeno não se restringia a algo que podemos sentir, perceber, inferir, lembrar, ou localizar na ordem espaço-temporal que o senso comum nos faz identificar como sendo o "mundo real". Fenômeno é qualquer coisa que aparece à mente, seja ela meramente sonhada, imaginada, concebida, vislumbrada, alucinada... um devaneio, um cheiro, uma ideia geral e abstrata da ciência... Enfim, qualquer coisa (SANTAELLA, 2000, p.7)

A oficina é dividida em seis partes e procura estimular, a princípio, cada um dos sentidos, bem como relações e reações corpóreas (pensando assim numa relação de primeiridade com relação ao objeto), em seguida, os participantes são estimulados a buscar sensações e memórias despertadas pelo objeto, levando a uma relação de secundidade com o objeto, ou seja, o signo aponta para a dimensão experiencial de sensações e ideias, e num último momento, todas as experiências anteriores são condensadas de forma a criar um personagem, ou seja, um ser com personalidade, narrativa e história completas. Uma espécie de "argumento" (SANTAELLA et al. 2016). No processo, um novo signo é gerado: o interpretante, o que possibilita a continuidade do processo de semiose.

Conforme afirma Plaza, três niveis de leitura do signo acontecem simultaneamente, havendo apenas algumas relações de predominância em cada uma delas: 
Assim como o pensamento, as linguagens contêm três aspectos: a) as suas qualidades materiais que dão ao pensamento sua qualidade; b) a aplicação denotativa ou conexão real que põe um pensamento-signo em relação a outro; c) a função representativa. Fazendo distinção nítida entre as qualidades materiais do signo, seu objeto e significado, Peirce estabeleceu que todo processo signico opera por relações triádicas entre esses três elementos de semiose. (PLAZA, 2003, p. 21)

O "casaco" é trabalhado em sua condição de artefato a partir das três categorias estipuladas acima, que, apesar de inspiradas pelas categorias fenomenológicas, vale ressaltar que não tratam da mesma coisa. Assim, partimos de uma interseção entre os campos para gerar uma reflexão sobre a primeiridade, a secundidade e a terceiridade, e consequentemente levar ao processo de semiose, como elucida Santaella:

Apesar da variabilidade material de cada fenômeno específico, contudo, o substrato lógico-forma das categorias se mantém sempre. Daí Peirce ter finalmente fixado para elas a denominação logicamente mais pura de "primeiridade, secundidade e terceiridade". O primeiro está aliado às ideias de acaso, indeterminação, frescor, originalidade, espontaneidade, potencialidade, qualidade, presentidade, imediaticidade, mônada... O segundo às ideias de força bruta, ação-reação, conflito, aqui e agora, esforço e resistência, diade.... O terceiro está ligado às ideias de generalidade, continuidade, crescimento, representação, mediação, tríada.

É justamente a terceira categoria fenomenológica (crescimento contínuo) que irá corresponder à definição de signo genuino como processo relacional a três termos ou mediação, o que conduz à noção de semiose infinita ou ação dialética do signo. (1995, pp.17-18)

É importante ressaltar que a escuta é estimulada durante a ação, ou seja, dá-se ênfase a um exercício de percepção do objeto. É preciso estimular que os participantes notem e sejam capazes de perceber e trabalhar a partir da agência da própria materialidade. Para isso, durante o desenrolar da oficina são elucidadas e discutidas as questões de agência, ator-rede e vida, além de serem discutidas questões da virada ontológica discutidas pelos autores da antropologia acima citados. Assim, a oficina ocorre, idealmente, da seguinte maneira:

\subsection{VISÃO}

Pede-se que os participantes espalhem os casacos pela sala em diversas composições com o próprio espaço e com os objetos que nela já se encontram, como cadeiras, mesas e portas. A oficina pode ser ministrada em diversos tipos de espaço, tais como, sala de aulas, parques, museus; só é necessário que sejam lugares em que os participantes possam sentar e ouvir uns aos outros e ter uma superficie plana para que possam desenhar com conforto, como uma mesa ou mesma uma prancheta. Os casacos podem ser pendurados, dobrados cuidadosamente ou jogados no chão, mas é importante que fique claro que eles já compõem em si, enquanto corporeidade, no espaço.

Dessa forma, desde o primeiro momento, busca-se entender o casaco enquanto uma realidade corpórea. Cada estudante deverá escolher um casaco que não seja o seu e, a partir de então, a oficina se inicia, sendo solicitado que os participantes relatem tudo o que pos- 
sam ver sobre a vestimenta sem, no entanto, tocá-la. Isso acontece através de um relato por escrito, que pode ser feito em forma de diálogo, carta, poesia ou tópicos. Nesse processo, estimulamos que busquem outros gêneros literários e formas de compor suas narrativas no decorrer da oficina. Também pedimos que os estudantes desenhem o vestuário da maneira como ele se apresenta, tentando representar e adivinhar texturas, cores, formas, materiais, tamanho, detalhes.

Figura 3: Oficinas ministradas em Março de 2019 na Fundação Clóvis Salgado _MG.
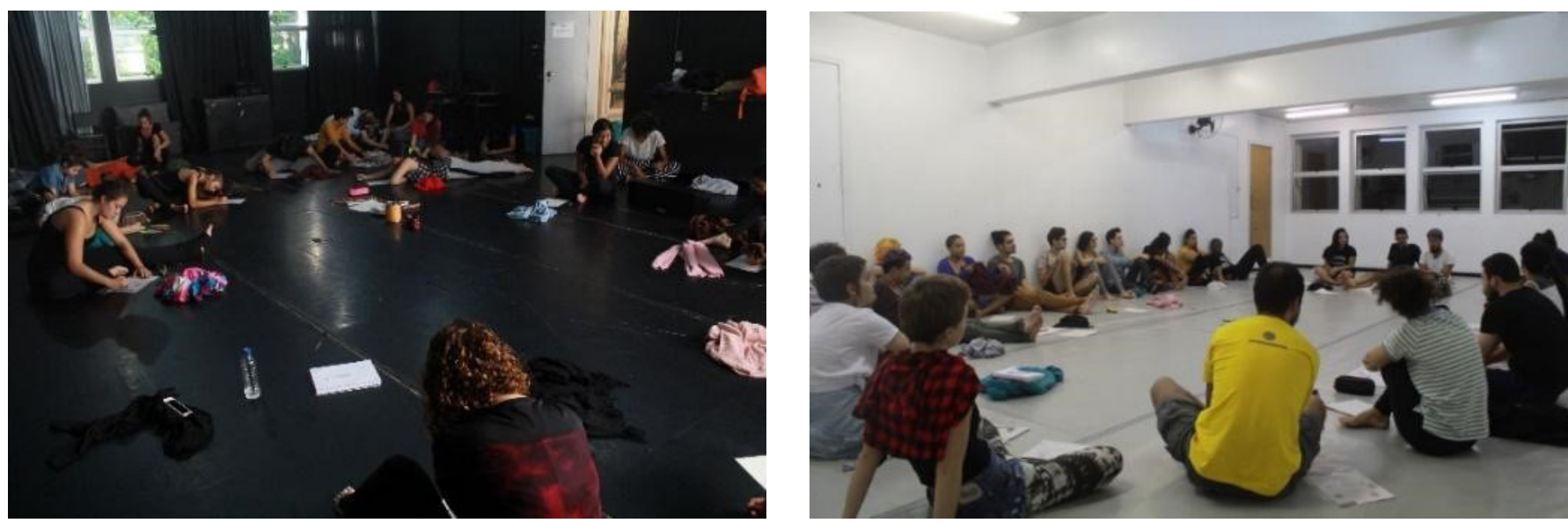

Fonte: Autoras. 
Algumas perguntas vão sendo feitas ao longo do processo, como, por exemplo: Qual é o tecido? Você sabe o nome dos tecidos que utiliza cotidianamente em suas roupas? Qual impressão o casaco te causa? Como você acha que esse modelo foi feito e costurado: Grande indústria? Pequena produção? Autoral ou comercial? Quanto anos acha que tem? Qual o peso? Objeto de slow fashion ou fast fashion? Quanto acha que custou? Porque você acha que foi escolhido por esse objeto? Que tipo de elementos te atraem nesta peça? Pede-se que o participante relate tudo que o olhar pode dizer sobre a peça. Após esta e cada uma das próximas etapas descritas, os resultados, respostas e questionamentos que surgiram são compartilhados com o grupo a partir de um processo de escuta e troca.

\subsection{OLFATO / TATO}

Em seguida, solicita-se aos participantes que peguem os casacos e, de olhos fechados, passem a explorá-los sensorialmente, sentindo seus cheiros, texturas e toques. O casaco tem forro? Como é construído por dentro? As texturas, tamanhos e formas correspondem às impressões visuais que você teve na primeira etapa? Você crê que esse casaco é muito usado ou estava guardado? É formal ou casual? Qual a composição dos tecidos? O tamanho? O peso? Como é costurado? Há remendos? Falhas, furos? Quantos anos você acha que tem? Você o usaria? Algo o surpreendeu em relação ao que a visão apresentou? Pede-se, então, que o participante anote e desenhe as sensações causadas sem a visão e, em seguida, que desenhe um detalhe relevante do casaco, ou ilustre os sons produzidos pelo seu casaco, numa tentativa de que sintam efeitos sinestésicos.

É crucial destacar a importância de que a visão seja retirada nessa etapa do processo para que os outros sentidos possam ser vivenciados e incentivados de forma expandida e intensificada. É possivel notar que ao retirar o sentido da visão e focar nos demais sentidos, emoções mais profundas e subjetivas vêm à tona. Em várias ocasiões, participantes se emocionaram nesta etapa ao reconhecer nos cheiros ou texturas do tecido memórias próprias.

\subsection{FORMA \& FUNÇÃO}

A partir do toque, sugere-se que os participantes pensem e relatem qual a função de um casaco. Perguntas: Você acha que esse casaco cumpre com sua função? Discorra sobre sua resposta. É um casaco velho ou novo? Caro ou barato?

Você usaria essa jaqueta? 


\subsection{ERGONOMIA-ANTIERGONOMIA}

Nessa etapa os participantes experimentam e vestem a jaqueta. Pergunta-se: cabe em você? Te deixa confortável? Se não, por quais motivos te causa desconfortos? É pequena? Como você se sente usando algo de outra pessoa? É sugerido que descrevam as sensações que vestir (ou tentar vestir) esse casaco causa e que explorem a ergonomia e usabilidade da peça.

Pergunta-se em seguida: há outras maneiras de usar o casaco? Experimente ao menos três modos diferentes de vestir o casaco. Solicita-se que os participantes experimentem vestir o casaco de uma maneira inusitada e antiergonômica e, a partir desta experiência, discute-se questões de maleabilidade da roupa e/ou da adaptação dela ao corpo.

Em seguida, a partir do questionamento: "crê que esta peça cumpre sua função e te protege suficientemente do frio? ", relacionado, ainda, à questão da forma e da função tão discutidas no ensino do design, a oficina propõe pensar as questões estéticas bem como a refletir sobre os corpos-sujeitos que habitam as peças. Busca-se gerar empatia sobre como, por exemplo, pessoas que têm sobrepeso se sentem numa loja em que nada foi feito para seus corpos e como a antiergonomia, ou seja, quando a roupa causa desconforto, pode ser um processo de redescoberta de si e do objeto.

Figura 4: Oficina ministrada em Julho de 2018 no SENAC_MG
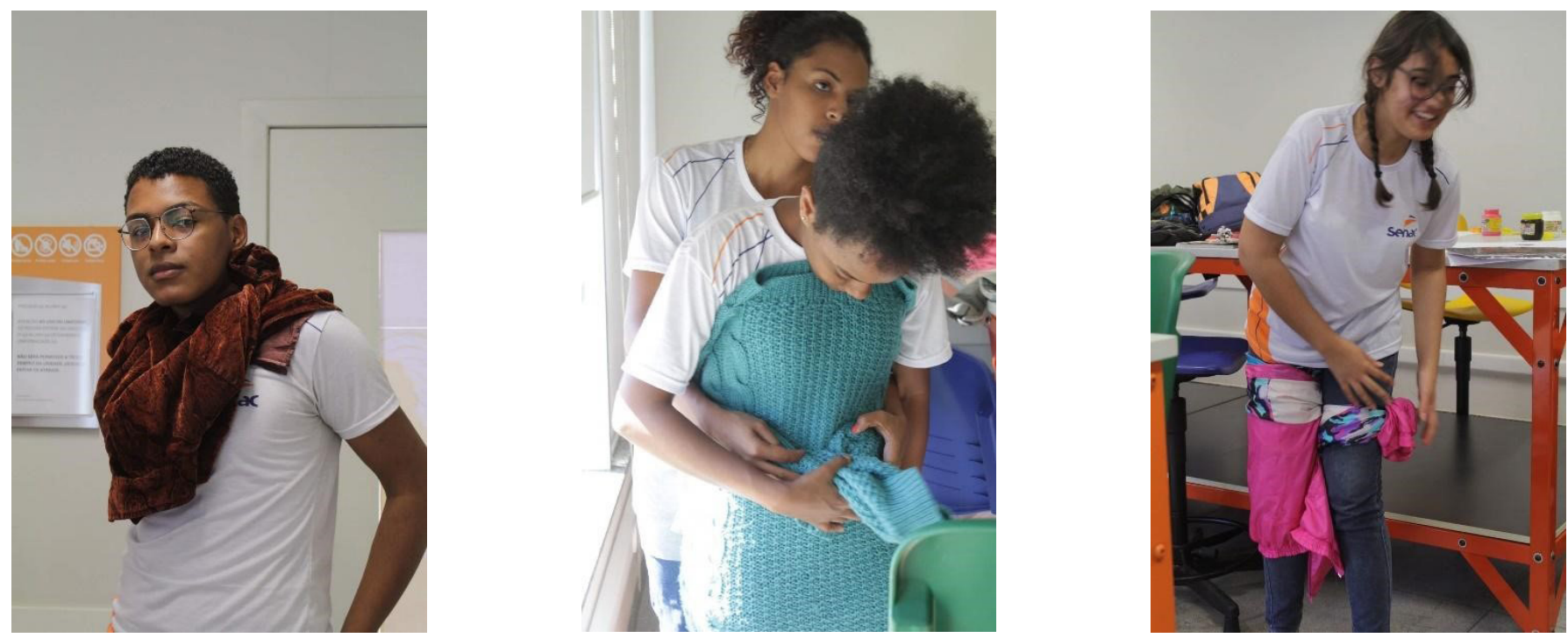

Fonte: Autoras. 


\subsection{O SEGREDO DO CASACO}

Nessa fase, solicita-se ao participante que pergunte um segredo ao seu casaco. Real ou "inventado". Novamente ressalta-se que o processo é de diálogo com o casaco e as respostas podem ser bastante inusitadas. É importante ressaltar que para se descobrir o segredo é preciso que haja escuta, uma escuta que se dá a partir de todos os sentidos. Assim, pede-se ao participante que descubra algo que somente a pessoa sabe sobre essa materialidade do casaco ou sobre sua história. Nessa etapa é destacada a intimidade que foi sendo criada com a peça no decorrer da oficina, pois apenas sabemos os segredos daqueles de quem somos intimos.

\subsection{CONVERSA / ILUSTRAÇÃO / SEMIOSE}

Finalmente, convidamos os participantes a elaborarem um processo imaginativo e de relato sobre a ideia de quem esse casaco seria se fosse um ser vivo, ou seja, tanto uma pessoa, um ser humano ou um outro tipo de ser: um alienígena, um monstro, uma entidade ou mesmo uma divindade. Sugere-se que o participante mande uma carta para seu casaco ou dialogue com ele de alguma forma, para, em seguida, introduzi-lo e apresentá-lo ao resto do grupo.

Um detalhe relevante a ser ressaltado para os participantes é que a proposta não trata de desenhar o dono da jaqueta ou qualquer pessoa vestindo a jaqueta; a intenção é explicar a personalidade do seu casaco. Personificá-lo. A ideia é que cada um converse com seu casaco, crie um diálogo, escute o que ele tem a dizer e quem ele é, qual é sua personalidade, o que ele gosta de fazer no seu tempo livre, seus defeitos, qualidades, medos, paixões. Os participantes usam sua imaginação e o que o próprio "design", o tecido, o acabamento, as texturas as costuras dizem para descobrir a possivel idade e tudo mais que a sua jaqueta tenha a dizer para construir uma personalidade para ela. 
Figura 5: Oficina ministrada em Março de 2019 na Fundação Clóvis Salgado _MG



Fonte: Autoras. 
Nessa etapa, traça-se livremente o perfil que cada casaco teria, caso fosse um ser vivo: uma pessoa ou criatura viva como, por exemplo, um alienígena, uma entidade espiritual ou um monstro. Podem ser utilizadas aqui diversas técnicas, tais como colagens, anotações, e deve-se explorar o potencial inovador e criativo da atividade, mas mantendo-se fiel ao casaco e ao que sua materialidade propõe. Tenta-se então descobrir tudo que possa sobre essa "pessoa", nome, idade, profissão, onde mora, familia, filhos, etc. Produz-se assim, uma espécie de tradução Intersemiótica, que segundo aponta Julio Plaza:

Todos os fenômenos de interação semiótica entre as diversas linguagens, a colagem, a montagem, a interferência, as apropriações, integrações, fusões e re-fluxos interlinguagens dizem respeito às relações tradutoras intersemióticas mas não se confundem com ela. Trazem, por assim dizer, o gérmen dessas relações, mas não as realizam, via de regra, intencionalmente. Nessa medida, para nós, o fenômeno da TI estaria a linha de continuidade desses processos artísticos, distinguindo-se deles, porém, pela atividade intencional e explícita de tradução. (2003, p.12)

Assim, a oficina funciona como uma tradução intersemiótica, uma metacriação como um pensamento atuando em signos em que há um trânsito dos sentidos; nas palavras do autor, uma "transcrição de formas na historicidade " (PLAZA, 2003, p.21).

Ao final da oficina é realizado um debate sobre as relações surgidas com o objeto. É discutido como a roupa modifica nossa visão sobre outrem e como alguém pode modificar como vemos uma roupa, quais são as relações que se estabelecem entre usuário e objeto e como essas leituras se constituem. A questão da usabilidade é levantada, especialmente para aqueles cujo casaco não serviu. Prossegue-se incentivando a pensar em pessoas acima do peso, que quase nunca encontram roupas de sua numeração em lojas convencionais, muito menos nos padrões de naturalização de um tipo de corpo criado e reforçado pela indústria da moda. Discute-se ainda as sensações do tecido e a sensação de poder ou vergonha que uma roupa pode trazer. O processo de construção e costura das roupas num mercado globalizado. Nesse momento, a oficina também retoma questões antropológicas de agência e vida na cultura material, além do afeto que nutrimos, ou não, pelos nossos objetos cotidianos.

Ao longo da oficina, busca-se um processo de semiose que parta da primeiridade, do sentimento, caminhe para a dimensão existencial/material do objeto casaco, numa ação de secundidade, para tentar, como arremate, chegar a uma posição interpretativa, na terceiridade. Este processo torna-se possível por meio do incentivo à desconstrução da relação diádica do sujeito com o objeto de conhecimento casaco, o que permite a emergência e o resgate de um outro tipo de olhar que reontologiza o objeto casaco, transformando-o, em alguma medida, em sujeito. Tal transmutação do olhar aproxima-se do que afirma Stallybrass:

O problema para Marx era, pois, não o fetichismo como tal, mas antes, uma forma especifica de fetichismo que tomava como seu objeto não o objeto animado do amor e do trabalho humanos, mas o não-objeto esvaziado que era o local de troca. No lugar do casaco havia um valor transcendental que apagava tanto o ato de fazer o casaco quanto o ato de vesti-lo. (2012, p.46)

Finalmente a oficina se encerra com essa tentativa de resgate da "magia" perdida, de repensar esse "fetiche" como conceito (...) elaborado para demonizar o apego supostamente 
arbitrário dos africanos ocidentais aos objetos materiais. O sujeito europeu foi constituído, através da denegação do objeto" (STALLYBRASS, 2012, p.42), do restauro desse fetiche relativo ao amor e ao trabalho, reconhecendo que os objetos têm vida e fazem parte ativamente da nossa construção social. Ou seja, do reconhecimento de que roupas/objetos não são meras coisas, mas que possuem uma vida social e afetiva, carregando memórias e valores agregados muito além dos da mercadoria, de modo a fazer repensar o fetiche a partir da magia das coisas e não do lugar de objetificação.

Figura 6: Oficina ministrada em Maio de 2018 na Universidade Autônoma do México.

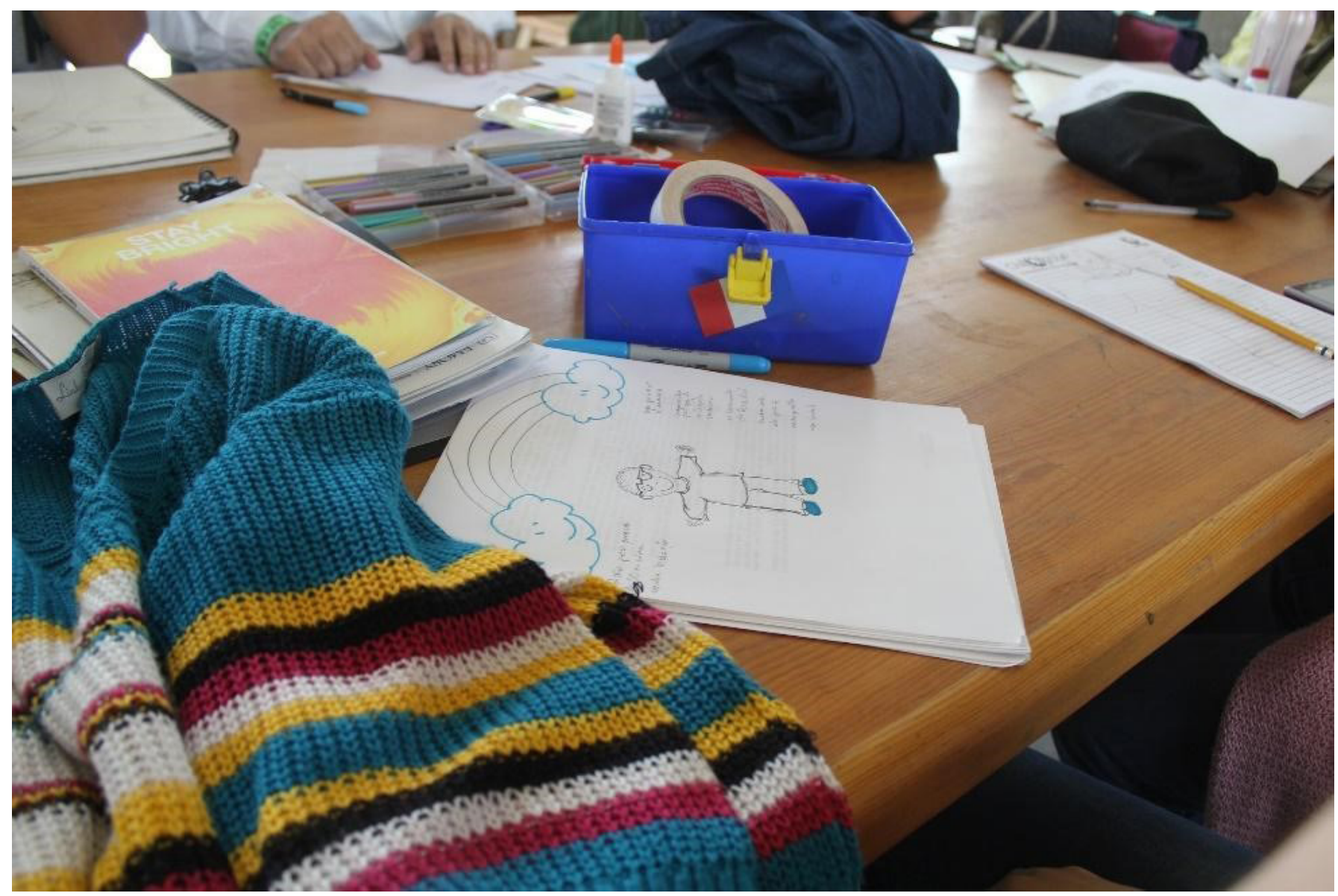

Fonte: Autoras. 


\section{A MODA E O DESIGN ENTRE A ANTROPOLOGIA E A SEMIÓTICA}

O lugar do objeto casaco, conforme foi apresentado no decorrer das discussões anteriores, sugere que se torna possivel pensar os modos de configuração e vivência da oficina com base nos paradigmas conceituais da Semiótica peirceana e da Antropologia. Autores como Barad, Miller e Ingold têm em comum o fato de reconhecerem, assim como Peirce, que os objetos/as coisas/ a cultura material possuem vida / ou agência. Cada uma dessas visões tem suas particularidades, de certa forma até dissonantes, de como essas relações ocorrem e de que maneira devem ser denominadas e sistematizadas. Todavia, os autores têm em comum o fato de reconhecerem a agência/vida e participação do objeto nos emaranhados sociais. A versão para a qual todos eles, de alguma maneira, convergem e com a qual nós concordamos parece poder ser resumida na seguinte colocação de Miller:

\footnotetext{
O argumento central, aqui, é um paradoxo: a melhor maneira de entender, transmitir e apreciar nossa humanidade é dar atenção à nossa materialidade fundamental. Talvez pareça que isso só vale para o nosso presente particular - uma consequência da escala absoluta do consumo contemporâneo e suas implicações para o ambiente e outros debates éticos. Não acredito que seja o caso. Vou argumentar que sociedades não industriais são culturas tão materiais quanto a nossa. Esse livro fala de sociedades de consumidores e não de consumidores. (MILLER, 2013, pgs. 10-11)
}

A oficina propõe, portanto, um olhar aprofundado para um objeto cotidiano: dar atenção à materialidade é, possivelmente, uma maneira de apreciar e nos conectar à nossa humanidade.

\section{CONSIDERAÇÕES FINAIS}

A partir do fragmento acima destacado e das considerações postas neste artigo, é possivel observar a proposta da oficina como recurso artístico capaz de aprofundar as relações que se têm estabelecido com o objeto por meio dos novos olhares lançados pelos estudos da semiótica e da antropologia quando propõem modos de superar o par opositivo sujeito $X$ objeto. Essa visão que entrelaça signo e cultura repercute, ainda, na possibilidade de se compreender a intração descrita por Barad (2007) a partir desta experiência de prática-reflexiva.

Ao trazer o debate para o campo do design, que é o pensar do projeto, por vezes ligado ao objeto, mas não somente a este, uma questão que se coloca é a de como o designer pode se valer dos conceitos de agência/vida/participação propostos pelos estudos da Antropologia e pela geração de semiose, a partir das contribuições da Semiótica, para propor/projetar uma relação mais profunda dos usuários/corpos com os produtos, pensando no objeto como parte dessa rede de semiótica.

Dessa forma, constrói-se o convite para o design e a moda unirem-se à antropologia e à semiótica no reconhecimento da agência dos objetos, de modo a estabelecerem um encontro dialógico que poderá auxiliar na construção de um processo expandido de compreensão e relação com a cultura material. 


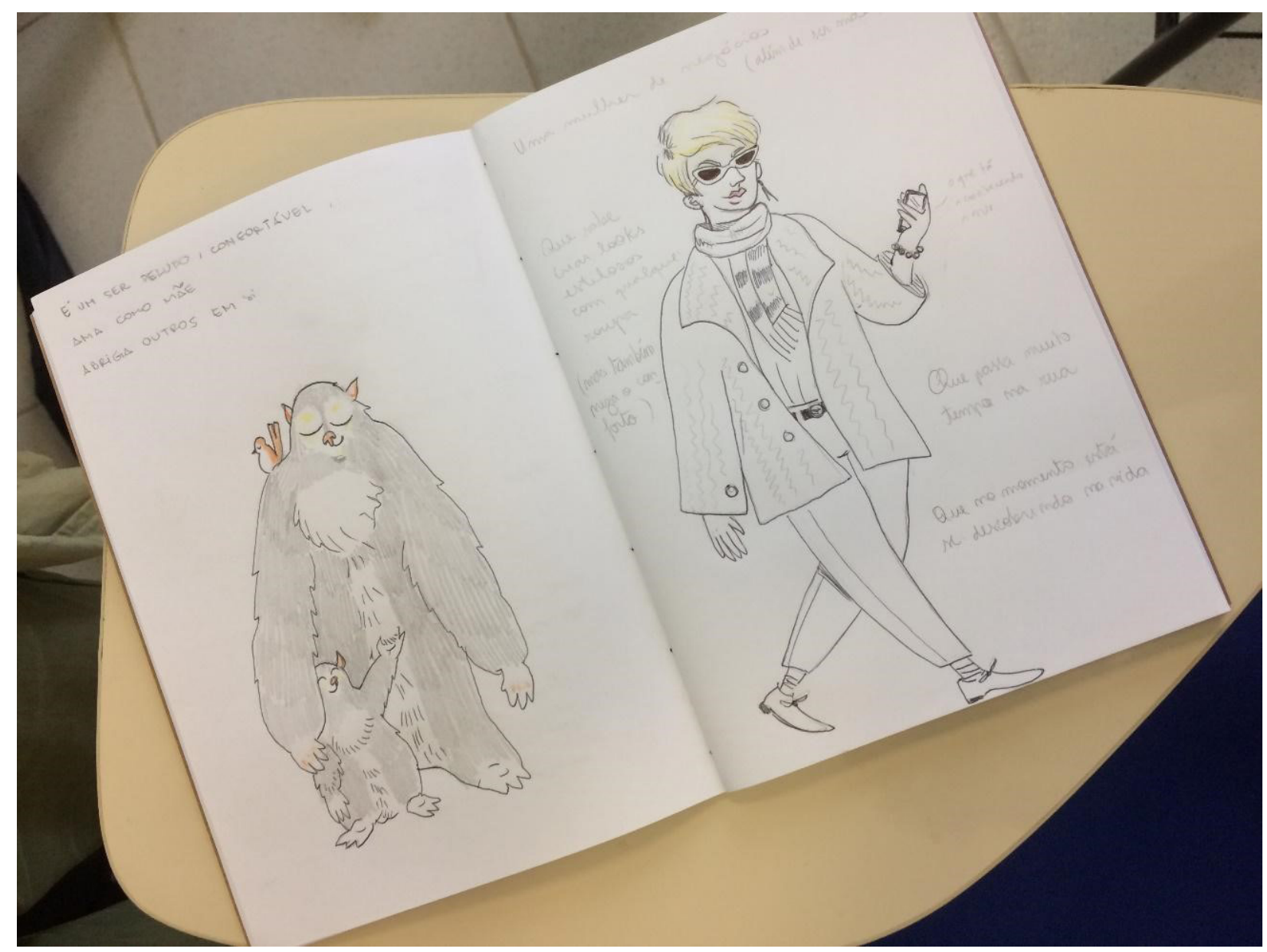

Fonte: Autoras.

O design, enquanto campo que reflete as relações, sobretudo formais, entre corpo e objetos, projeta caminhos para que essa relação entre usuários e coisas ocorra de uma maneira eficiente, confortável e "atraente". Os mais diversos objetos que nos circundam e que, como iluminam as teorias já citadas, tem agência. Como afirma Flusser, os objetos, nessa relação de consumo vigente, passam a ser obstáculos para remover obstáculos, alavancas que contra-atacam (2007). Ainda segundo Flusser, isso ocorre porque muitas vezes não exercitamos o olhar do designer, de enxergar além das necessidades básicas do presente (2007). 
A oficina inspirada no livro O casaco de Marx busca articular esses três olhares: o da antropologia através do realismo agencial (BARAD, 2007), o da semiótica a partir do desvelar do objeto, o signo casaco, utilizando como interpretante inicial o olhar sentinela do designer, esse que busca ver além de uma coisa para entender o que está contido na relação que se pode estabelecer com ela.

Como afirma Latour: "Definir os humanos significa definir as embalagens, os sistemas de suporte de vida, o Umwelt que os permite respirar" (2014, p.12). Ou seja, socialmente não existimos sem os artefatos/objetos/máquinas que nos cercam. É importante usá-los para expandir nossas capacidades sensoriais e relacionais com o mundo, ao invés de atrofiá-las. Assim propõe-se uma relação mais afetiva com a materialidade de um casaco, a partir da intração (BARAD, 2007) ou seja, da constituição mútua de sujeito e objeto que passam a se constituir em novo fenômeno a partir do encontro.

Ao refletir sobre essa intração a partir do casaco, torna-se possivel expandir essa percepção para qualquer objeto do cotidiano. A percepção da agência dos objetos poderia gerar outras possibilidades para as relações com os objetos, para além de uma relação que se encerra num consumo sem reflexão.

Ancorada nesses princípios, a oficina, em diversas ocasiões, apresentou momentos emocionantes nos quais as pessoas, ao se reconectarem com suas memórias, passaram efetivamente a se interessar em repensar e refletir de uma forma mais profunda sobre seus modos de se relacionar com a materialidade e sua posição de agentes junto aos objetos na sociedade de consumo.

De relatos criativos a questionamentos profundamente transformadores, em cada uma das edições acontecem trocas de ideias, reflexões e sentimentos inéditos e inusitados que levam a própria oficina à um processo de semiose, gerando outros interpretantes para si mesma que vão sendo adicionados aos seus processos, de modo a transformá-la a cada (re)edição.

Além disso, em termos experimentais, a oficina se constituiu como um interessante exercício de expressão gráfica, ao gerar diversos materiais criativos tais como a dramaturgias, poemas, colagens, desenhos e pinturas e transitar por outras disciplinas como a Literatura, a Sociologia, a Arqueologia e as Artes.

Esperamos que a partir desse relato seja possivel a outros professores e profissionais interessados replicar sua metodologia e descobrir novas questões propositivas para um tópico tão latente e instigante quanto nossa relação com a cultura material e com os objetos de design. ${ }^{2}$

\footnotetext{
${ }^{2}$ Este artigo foi corrigido e revisado por Maria das Dores Pereira Santos, licenciada em Letras pela UFPB, é mestre em Literatura: crítica literária pela PUC-SP e doutoranda em Literatura pela UnB. É professora na Universidade do Estado da Bahia - UNEB, desde 2011.
} 


\section{Referências Bibliográficas:}

BARAD, Karen. Meeting the Universe Halfway: Quantum Physics and the Entanglement of Matter and Meaning. London: Duke University Press, 2007.

BARROS, Manoel de. Livro sobre nada. Rio de Janeiro: Editora Record, 1996.

FLUSSER, Vilém. O mundo codificado. São Paulo: Cosac Naify, 2007.

FRANCO, Juliana Rocha. Cartografias criativas: da razão cartográfica às mídias móveis. Curitiba: Appris, 2019.

FRANCO, Juliana Rocha; BORGES, Priscila Monteiro. O real na filosofia de C. S. Peirce. Teccogs: Revista Digital de Tecnologias Cognitivas, TIDD | PUC-SP, São Paulo, n. 12, p. 66-91, jul-dez. 2015.

FRANCO, J. , NEVES B. The distributed performance of artefactual representation by mobile video in Brazil. Janus 2017- A comunicação mundializada. 2017.

GELL, Alfred. Arte e Agência. São Paulo: Ubu, 2018.

INGOLD, Tim. Trazendo as coisas de volta à vida: Emaranhados criativos num mundo de materiais. Horizontes Antropológicos, Porto Alegre, ano 18, n. 37, p. 2544, jan./jun. 2012.

Bruno. Um Prometeu cauteloso? Alguns passos rumo a uma filosofia

do design. Agitprop n.58 (ano 6), 2009.

LE BRETON, David. Adeus ao Corpo: Antropologia e Sociedade. Campinas: Papirus, 2003.

MEARLEAU PONTY, Maurice. Fenomenologia da Percepção. São Paulo: Martins Fontes, 1999.

MILLER, Daniel. Trecos, troços e coisas: estudos antropológicos sobre a cultura material. Rio de Janeiro: Zahar, 2013.

PLAZA, Julio. Tradução Intersemiótica. São Paulo: Perspectiva, 2003.

SANTAELLA, Lucia. Teoria Geral dos Signos: Semiose e autogeração. São Paulo: Cengage Learning, 1995. 
SANTAELLA, Lucia et al. Por uma semiótica não-tergiversante: análise do site Conductor-MTA. me. LÍBERO. ISSN impresso: 1517-3283/ISSN online: 2525-3166, n. 28, p. 37-76, 2011.

SARAMAGO, José. Objecto- Quase. São Paulo: Companhia das Letras, 1998.

STALLYBRASS, Peter. O casaco de Marx: roupas, memória, dor. - 3. ed. - Belo Horizonte: Autêntica Editora, 2008.

TILLEY, Chris. Do corpo ao lugar à paisagem: uma perspectiva fenomenológica. Belo Horizonte: Vestígios, n 8, vol 1. jan-jun, 2014.

UEXKÜLL, Thure von. The Theory of Meaning. Trad. inglesa de Thure von Uexküll. Semiotica,2010. 